\title{
VIAGENS NA MINHA TERRA E PETER PAN: A AUTOTEORIZAÇÃO LITERÁRIA E SUAS RELAÇÕES COM O ENSINO
}

\section{VIAGENS NA MINHA TERRA AND PETER PAN: LITERARY SELF- THEORIZATION AND ITS RELATIONS TO TEACHING}

\author{
Taciane Ienk ${ }^{*}$ \\ Rosana Apolonia Harmuch ${ }^{* *}$ \\ O leitor e a leitura tornam-se, hoje, objetos de \\ reflexão teórica, até mesmo no interior do próprio \\ texto literário.
}

(OCEM, 2007, p. 65).

\begin{abstract}
Resumo: Partindo do pressuposto de que o principal conflito no ensino de Literatura no Ensino Médio é o grande enfoque na história da literatura, viu-se a necessidade de pensar o texto literário como protagonista. Entende-se que a abordagem exclusiva da história da literatura diminui a aparição do texto literário nas aulas, o que faz com que os alunos não tenham contato com o objeto de estudo da disciplina de Literatura, a obra literária. Com o intuito de colocar teoria e literatura lado a lado, optou-se por articular o mecanismo de autoteorização. Esse mecanismo visa abordar a teoria a partir das próprias obras literárias. Para explorá-lo foram selecionadas as obras Viagens na minha terra, de Almeida Garrett, e Peter Pan, de James Barrie. Como resultado das reflexões, será discutido de que forma a autoteorização literária contribui com o ensino de literatura no Ensino Médio. Serão utilizados: Culler; Volobuef; Jouve; $O C E M$; e Rouanet.
\end{abstract}

Palavras-chave: Ensino Médio. Ensino de Literatura. Obra Literária. Autoteorização literária.

\begin{abstract}
Based on the assumption that the main conflict in the teaching of Literature in High School is the great focus in the history of literature, we saw the need to think the literary text as protagonist. It is understood that the exclusive approach of the history of literature diminishes the appearance of the literary text in the classes, which causes that the students do not have contact with the object of study of the discipline of Literature, the literary work. In order to put theory and literature side by side, it was decided to articulate the mechanism of self-theorization. This mechanism aims to approach the theory from the literary works themselves. To explore it were selected the works Viagens na minha terra and Peter Pan by James Barrie were selected. As a result of the reflections, it will be discussed how the literary self-theorization contributes to the teaching of Literature in High School. Will be the basis: Culler; Volobuef; Jouve; OCEM; and Rouanet.
\end{abstract}

Keywords: High School. Literary teaching. Literary work. Literary self-theorization.

\section{Introdução}

Entende-se que, ao nos referirmos ao ensino de Literatura na escola, mais especificamente no Ensino Médio, é comum atrelarmos à essa disciplina o estudo das escolas literárias, da história da Literatura. Esse fato representa um conflito, pois a

\footnotetext{
* Mestranda do Programa de Pós-Graduação em Estudos da Linguagem na Universidade Estadual de Ponta Grossa, UEPG (2018), Ponta Grossa, PR. Licenciada em Letras Português/Espanhol pela Universidade Estadual de Ponta Grossa, UEPG (2017), Ponta Grossa, PR. E-mail: taci.ienk@gmail.com ** Doutora em Estudos literários pela Universidade Federal do Paraná, UFPR (2006), Curitiba, PR. Atualmente é professora associada na Universidade Estadual de Ponta Grossa, UEPG, Ponta Grossa, PR, e docente no Programa de Pós-Graduação em Estudos da Linguagem, da mesma instituição. E-mail: rosanaharmuch@hotmail.com
} 
abordagem trabalhada em sala de aula volta-se para o ensino da história da literatura, deixando para o texto literário e para a teoria papéis secundários, o que não deveria acontecer.

Partindo desse pressuposto, pretende-se discutir de que forma a obra literária e a teoria podem dividir espaços iguais dentro da sala de aula. Para isso, é importante destacar o que os documentos oficiais dizem a respeito do ensino de Literatura no Ensino Médio.

O principal conceito que articulará esta pesquisa é o da autoteorização. Entende-se que trabalhar com obras autoteorizantes permite o contato simultâneo entre Literatura e teoria literária, uma vez que essas obras falam sobre sua própria estrutura, se auto explicam. Com o intuito de pensar o ensino de Literatura a partir das próprias obras literárias, optou-se por explorar neste artigo a autoteorização em Viagens na minha terra, de Almeida Garret, e em Peter Pan, de James Matthew Barrie.

Para investigar de que forma a autoteorização literária contribui para o ensino de literatura no Ensino Médio, serão utilizados como fundamentação teórica Culler (1999); Volobuef (1999); Jouve (2002); as Orientações Curriculares para o Ensino Médio (2006); Rouanet (2007).

\section{A autoteorização literária em Viagens na minha terra e em Peter Pan}

Para adentrarmos no mecanismo da autoteorização literária é importante ter em vista o conceito de teoria na literatura, pois é a partir dela que a autoteorização (ou ironia romântica, como veremos mais adiante) "nasce". Para mostrar o que se entende por teoria achou-se pertinente trazer para esta pesquisa as contribuições de Jonathan Culler (1999) - capítulo I O que é teoria da obra Teoria Literária: uma introdução sobre o assunto.

Culler (1999) salienta que ao contrário do que se pensa a teoria não é uma explicação sobre a origem da literatura ou sobre os métodos para seu estudo, ela é interdisciplinar; analítica e especulativa; uma crítica do senso comum; "é reflexiva, é reflexão sobre reflexão", ela se refere a "obras que conseguem contestar e reorientar a reflexão em campos outros que não aqueles aos quais aparentemente pertencem [...] obras consideradas como teoria têm efeitos que vão além de seu campo original". (CULLER, 1999, p. 12-23), ou seja, a teoria se distancia da "explicação" e se aproxima da reflexão.

Durante muito tempo houve uma grande preocupação com o leitor, porém, é com a aparição do romance no século XIX que os escritores declaram essa preocupação e dão ao leitor um "papel ativo" na experiência da leitura. Sendo assim, é possível dizer que o século XIX representa um marco na história da literatura.

Até o fim do século XVIII, os textos literários consumidos eram as epopeias, no entanto, como eram financiadas pela igreja ou pela burguesia, eram lidas apenas por pessoas importantes da alta sociedade e/ou por aqueles que eram alfabetizados. A epopeia apresentava (e ainda apresenta) relevância para seu país de origem e, consequentemente, para a História mundial. Ainda que mesclassem em seu conteúdo a mitologia, as epopeias tinham um compromisso com a verdade.

Diferentemente da epopeia, o romance não tem nenhum compromisso com a verdade ou em "pintar" a vida real/realidade. Isto é, ele pode trazer em sua narrativa fatos reais e/ou ficcionais, é escrito em prosa e a aparição de novos personagens no 
decorrer da trama surge de acordo com a sua pertinência. Sem dúvida o romance era uma novidade.

Para muitos esse novo gênero foi considerado imitação, representação, indicação, sugestão ou expressão da realidade. É nesse sentido que nascem novas preocupações e interesses. Os romancistas viram, então, a necessidade de discutir dentro das próprias narrativas questões como realidade versus ficção; o conceito de verdade; o próprio fazer literário; a literatura de modo geral etc., tendo como alvo principal a educação do leitor. Todas essas discussões que começaram a ser abordadas pelos romancistas formam o âmbito da teoria, pois, como aponta Culler (1999, p.24), "a teoria é ela própria o questionamento dos resultados presumidos e dos pressupostos sobre os quais eles se baseiam".

Sendo o tema do fazer literário pertinente ao cenário atual do ensino de literatura no Brasil, optou-se por abordá-lo e mostrar como ele pode ser relevante para a formação do leitor. $\mathrm{O}$ fazer literário se refere às discussões trazidas dentro das próprias obras. A essas discussões chamaremos autoteorização literária. Essa foi a denominação adotada, porém, existem outras maneiras de se referir às obras que se auto explicam e que trazem reflexões/discussões sobre literatura, como por exemplo: ironia romântica, metaliteratura, metaficção etc.

Karin Volobuef (1999, p. 91) refere-se à autoteorização como ironia romântica e, segundo ela, esse mecanismo "trata-se da ascendência do autor em relação à obra", pois é por meio de seus narradores que os autores pensam suas obras. Volobuef (1999) destaca, também, que a autoteorização literária ocorre dentro da obra literária, uma vez que o texto se interrompe para se auto explicar, ou seja, é literatura que discute sobre a própria literatura.

Nos momentos em que a obra está se auto explicando o leitor é convidado a participar da narrativa. É na autoteorização que o narrador troca ideias com o leitor ${ }^{1}$, no entanto, como bem aponta Volobuef (1999, p. 95), "mais do que simplesmente divertir o leitor (empírico) com comentários jocosos, seu narrador busca realmente refletir sobre o próprio texto, sobre o fazer poético, sobre a literatura em geral".

É importante ter em vista que a autoteorização

Não se esgota na mera interrupção do fluxo narrativo com o narrador dirigindo-se ao leitor. É, muito além disso, um recurso que se destina a fomentar uma constante discussão e reflexão sobre literatura - um processo do qual o leitor forçosamente participa. Essa participação é alcançada na medida em que o escritor destrói a ilusão de verossimilhança e desnuda o caráter ficcional da narrativa, chamando a atenção do leitor para como o texto foi construído. (VOLOBUEF, 1999, p. 98-99).

Em suma, pode-se perceber que mais do que se preocuparem em pintar a realidade tal como ela é, os romancistas do XIX também se preocupavam em promover reflexões sobre a própria literatura e que envolvessem o leitor. Nas obras do século XIX

\footnotetext{
${ }^{1}$ O leitor referido corresponde ao leitor modelo. Segundo Umberto Eco (1994), o leitor modelo é aquele que preenche os espaços vazios de uma narrativa e cumpre com as expectativas do narrador/autor; é o leitor que o autor tinha em mente, é o tipo ideal. Ainda de acordo com Eco (1994, p. 99), "o perfil do leitor modelo é desenhado pelo texto e dentro do texto".
} 
essa preocupação se tornou uma tópica ${ }^{2}$, pois a temática já estava/se fazia presente em diversos romances, como por exemplo em Amor de Perdição, de Camilo Castelo Branco, O primo Basílio, de Eça de Queiroz, Memórias póstumas de Brás Cubas, de Machado de Assis etc. Rouanet (2007) chamou os romances que se auto teorizam de shandianos, pois eles apresentam a mesma forma, são "feitos aos moldes", de Tristam Shandy, de Laurence Sterne.

Feitas as considerações referentes ao conceito de teoria e de autoteorização, nos aprofundaremos na análise das obras literárias Viagens na minha terra, de Almeida Garrett, e Peter Pan, de James Matthew Barrie, para que assim possamos exemplificar e mostrar como a autoteorização literária de fato se manifesta.

A primeira obra em análise, Viagens na minha terra, é um romance português escrito em 1843 por Almeida Garrett. Em linhas gerais:

O livro descreve o trajeto de Garrett pelo Ribatejo, de Lisboa ao Cartaxo, dali a Azambuja, até a chegada em Santarém. Esse percurso de navio, de carruagem e em lombo de mula não contém grandes aventuras. O livro é mais rico em reflexões sobre a decadência de Portugal que em episódios de viagem, e seu miolo é constituído pela história de amores de Carlos, soldado da causa liberal durante a guerra civil de 1831-34, com sua prima Joaninha, a "menina dos rouxinóis". (ROUANET, 2007, p. 19-20).

Em Viagens percebe-se a presença de três narrativas: a história da história do livro (tempo da enunciação); a viagem geográfica (tempo do enunciado); a história de Carlos, Joaninha (tempo do enunciado). Por apresentar mais de uma narrativa a obra possui dois tipos de narradores, o homodiegédico, em primeira pessoa, que narra a história e o heterodiegético, em terceira pessoa, que narra a história de Carlos e de Joaninha.

O conteúdo da história é logo anunciada pelo narrador (homodiegético): "Ainda assim, belas e amáveis leitoras, entendamo-nos: o que eu vou contar não é um romance, não tem aventuras enredadas, peripécias, situações e incidentes raros; é uma história simples e singela, sinceramente contada e sem pretensão." (GARRETT, 1997, p. 81). Contudo, no decorrer da leitura é possível perceber que a obra se trata muito mais do que uma "história simples" e "sem pretensão".

Ao longo das três narrativas o narrador tece, com um tom sarcástico, críticas a textos literários e, em especial, ao romance, como por exemplo no capítulo cinco em que ensina ao leitor a "receita" da "literatura original":

Sim, leitor benévolo, e por esta ocasião vou te explicar como nós hoje em dia fazemos a nossa literatura. Já não me importa guardar segredo; depois desta desgraça não me importa já nada. Saberás pois, ó leitor, como nós outros fazemos o que te fazemos ler. Trata-se de um romance, de um drama - cuidas que vamos estudar a história, a

\footnotetext{
${ }^{2}$ De acordo com Massaud Moisés, "na retórica clássica, os tópicos eram não só a matéria dos argumentos como também os lugares-comuns formais empregados pelos oradores na composição dos seus discursos (...) No século XX, Ernest Robert Curtius retomou o vocábulo e propôs um método fecundo de investigação baseado no topoi, agora entendidos como fórmulas estereotipadas de expressão e de pensamento, modos de dizer e de pensar que se transformaram "em clichês" de emprego universal na literatura, disseminados por toda parte, desde a Antiguidade clássica até o século XVIII" (MOISÉS, 2004, p. 447-448).
} 
natureza, os monumentos, as pinturas, os sepulcros, os edifícios, as memórias da época? Não seja pateta, senhor leitor, nem cuide que nós o somos. Desenhar caracteres e situações do vivo na natureza, colorilos das cores verdadeiras da história... isso é trabalho difícil, longo, delicado, exige um estudo, um talento, e sobretudo um tato!...

Não senhor: a coisa faz-se muito mais facilmente. Eu lhe explico.

Todo o drama e todo o romance precisa de:

Uma ou duas damas,

Um pai,

Dois ou três filhos, de dezenove a trinta anos,

Um criado velho,

Um monstro, encarregado de fazer as maldades,

Vários tratantes, e algumas pessoas capazes para intermédios.

$[\ldots]$

E aqui está como nós fazemos a nossa literatura original. (GARRETT, 1997, p. 55).

Em 1843, ano em que a obra foi escrita, o romantismo ainda estava se estabelecendo e é por essa razão que Garrett satiriza os romances da época, pois essa era uma maneira de discutir a literatura romântica da época, de teorizar e de mostrar para o leitor que nem tudo o que estava escrito na obra era de verdade.

No decorrer da leitura de Viagens na minha terra é possível perceber que a autoteorização se faz presente quase que integralmente, pois, além da ficção, do próprio romance, logo no início, no prólogo, a narrativa dá indícios de que está se auto explicando. Os trechos selecionados e apontados neste artigo como autoteorizantes fazem referência a autoridade do narrador dentro da narrativa, a crítica aos poetas e, obviamente, a literatura.

Como é comum nas obras autoteorizantes, o narrador se mostra dono de sua narrativa: "a minha opinião sincera e conscienciosa é que o leitor deve saltar estas folhas, e passar ao capítulo seguinte, que é outra casta de capítulo". (GARRETT, 1997, p. 54). Como manda na história, o narrador dá instruções ao leitor sobre os caminhos que ele deve seguir e as escolhas que deve tomar no momento da leitura da obra.

Como mencionado anteriormente, em vários momentos o narrador fala sobre a literatura, pois essa era uma maneira de teorizar a literatura a época:

Entraremos portanto em novo capítulo, leitor amigo; e agora não tenhas medo das minhas digressões fatais, nem das interrupções a que sou sujeito. Irá direita e corrente a história da nossa Joaninha até que a terminemos... em bem ou em mal? Dantes um romance, um drama em que não morria ninguém, era havido por sensabor; hoje há um certo horror ao trágico, ao funesto que perfeitamente quadra ao século das comodidades materiais em que vivemos. Pois, amigo e benévolo leitor, eu nem em princípios nem em fins tenho escola a que esteja sujeito, e hei de contar o caso como ele foi. Escuta. (GARRETT, 1997, p. 180).

Além de satirizar a literatura, o narrador critica, também, os poetas:

Inda assim! Não me esconjurem já o rapaz... Poeta, entendamo-nos; não é que fizesse versos: nessa não caiu ele nunca, mas tinha aquele fino sentimento de arte, aquele sexto sentido do belo, do ideal que só têm certas organizações privilegiadas de que se fazem os poetas e os 
artistas. [...] Infelizmente não se formulavam em palavras estes pensamentos poéticos tão sublimes. Por um processo milagroso de fotografia mental, apenas se pôde obter o fragmento que deixo transcrito. Que honra e glória para a escola romântica se pudéssemos ter a coleção completa! Fazia-lhe um prefácio incisivo, palpitante, britante... Punha-se-lhe um título vaporoso, fosforescente... por exemplo: - Ecos surdos do coração - ou Reflexos d'alma - ou Hinos invisíveis - ou Pesadelos poéticos - ou qualquer outro deste gênero, que se não soubesse bem o que era, nem tivesse senso comum. (GARRETT, 1997, p. 144-145).

No trecho destacado o narrador refere-se a carta de Carlos para Joaninha, porém, o leitor experiente compreende que se trata de uma crítica aos poetas.

No interior de Viagens encontramos constantes diálogos entre narrador e leitor. Algumas vezes esses diálogos são monólogos, o narrador se direciona ao leitor, mas esse não se manifesta. No trecho a seguir pode-se perceber que a manifestação do leitor é de suma importância:

Como hei de eu então, eu que nesta grave Odisséia das minhas viagens tenho de inserir o mais interessante e misterioso episódio de amor que ainda foi contado ou cantado, como hei de eu fazê-lo, eu que já não tenho que amar neste mundo senão uma saudade e uma esperança - um filho no berço e uma mulher na cova?... Será isto bastante? Dizei-o vós, ó benévolas leitoras, pode com isto só alimentar-se a vida do coração? — Pode sim. — Não pode, não. Estão divididos os sufrágios: peço votação. — Nominal? — Não, não. — Porquê? - Porque há muita coisa que a gente pensa e crê e diz assim a conversar, mas que não ousa confessar publicamente, professar aberta e nomeadamente no mundo... (GARRET, 1997, p. 83$84)$.

Pode-se pensar que o leitor se torna um cúmplice do narrador, ajudando-o a "montar" a estrutura, o curso, de sua obra. O leitor representa aqui, assim como a autoteorização literária, um mecanismo que guiará o leitor real dentro da narrativa.

A partir das considerações feitas é possível afirmar que Viagens na minha terra é uma obra que se auto explica, pois seu narrador discute em diversas passagens a respeito da literatura, conversa com o leitor e dá instruções ao leitor do caminho que ele deve seguir dentro da narrativa.

Assim como em Viagens na minha terra, Peter Pan nos direciona para inúmeras investigações, como realidade versus ficção, psicanálise, verdade etc., porém, a mais interessante, surpreendente e pertinente para este artigo, foi a da autoteorização.

Peter Pan é uma obra de ficção infantil publicada no ano de 1911 pelo inglês James Matthew Barrie. Basicamente, a obra narra as aventuras das crianças Darling: Wendy, Miguel e João, na Terra do Nunca. A convite de Peter Pan, as crianças partem para a ilha desconhecida e distante para vivenciar aventuras sem a presença, dos adultos, uma vez que a Terra do Nunca era habitada por meninos órfãos que não queriam crescer, mas que, sem mesmo notarem, se portavam como adultos.

Por mais que se trate de uma obra juvenil, Peter Pan é uma piscadela para os leitores experientes, pois, assim como Viagens na minha terra, carrega em sua narrativa muito além de uma boa história de ficção, carrega consigo temas importantes que podem contribuir para a formação do leitor. 
No que tange a autoteorização, pode-se perceber que ela se manifesta de três maneiras em Peter Pan: o narrador faz especulações sobre a narrativa e seu rumo; o narrador mostra que ele controla a narrativa; o narrador se direciona, constantemente, ao leitor.

Como é próprio da autoteorização, o autor de determinada obra discute, por meio de seu narrador, a própria estrutura da narrativa. Esse fato está presente em toda a narrativa de Peter Pan, pois o narrador de Barrie faz especulações a fim de decidir o percurso/rumo de sua narrativa:

Será que eles vão chegar ao quarto das crianças a tempo? Se chegarem vai ser muito bom para eles, e nós todos vamos dar um suspiro de alívio, mas não vai ter história. Por outro lado, se eles não chegarem a tempo, eu prometo solenemente que vai dar tudo certo no fim. (BARRIE, 2013, p. 60).

Além de decidir o rumo da narrativa, o narrador pede auxílio ao leitor para decidir qual aventura narrar:

Qual dessas aventuras a gente vai escolher? O melhor jeito é tirar cara ou coroa. Já tirei, e a aventura da lagoa ganhou. Isso quase me faz desejar que a aventura da ravina, do lobo ou de Sininho houvesse ganhado. É claro que eu poderia jogar a moeda de novo e fazer melhor de três; mas acho que é mais justo ficar com a da lagoa mesmo. (BERRIE, 2013, p. 120).

Apesar de pedir ajuda do leitor, o narrador decide por si só o que irá narrar. É nesse sentido que o narrador mostra seu domínio. Para Rouanet (2007, p. 49), "o narrador não deixa a menor dúvida sobre quem comanda o espetáculo". Mostrando o domínio sobre a obra, o narrador conduz o leitor à compreensão da narrativa e, consequentemente, de sua estrutura, do fazer literário.

Como controla a narrativa, o narrador interrompe as cenas importantes para narrar um fato aleatório. É nesses momentos que o leitor se converte em cúmplice do narrador:

Gancho saltou sobre a amurada do navio, pronto para se jogar no chão. Ele não sabia que o crocodilo o esperava, pois nós acabamos com a corda do relógio justamente para que ele não tivesse esse conhecimento. É um pequeno sinal de respeito nosso, agora que chegamos ao fim. (BARRIE, 2013, p. 219).

Em suma, é possível dizer que Peter Pan é uma obra que fala e discute sobre si mesma, pois seu narrador controla e debate constantemente com o leitor a respeito da estrutura interna da narrativa. Ao narrar a história de Peter Pan, o narrador discute o fazer literário, a própria estrutura da obra.

De maneira geral, ainda que tratem de assuntos diversos e apresentem estruturas e propostas diferentes, os romances têm alguns pontos em comum, como veremos a seguir. Como visto anteriormente, tanto em Viagens como em Peter Pan há narradores que controlam a narrativa, que discutem sobre literatura, que explicam a estrutura da obra e que fazem do leitor um cúmplice. Em ambos os romances a autoteorização está presente e desempenha um papel importante. 
Nos romances em estudo, os personagens já conheciam seus destinos. Em Viagens o narrador conhecia, ou achava que conhecia, o Pinhal da Azambuja dos livros, dos guias, das histórias que ouvia. Em Peter Pan as crianças Darling também conheciam a Terra do Nunca por meio das histórias que ouviam:

No início a sra. Darling não sabia, mas foi pensando em sua infância e se lembrou de um tal Peter Pan que, diziam, morava com as fadas. Existem histórias estranhas sobre ele [...] A sra. Darling acreditara em Peter Pan na época, mas, agora que era casada e cheia de bom senso, duvidava muito que tal pessoa existisse. (BARRIE, 2013, p. 20).

As crianças conheciam a reputação de Gancho sem mesmo terem ido à Terra do Nunca. Conheciam porque já o haviam visto nas histórias: "E foi então que Miguel começou a chorar mesmo, e até João só conseguiu falar com dificuldade, pois eles conheciam a reputação de Gancho.” (BARRIE, 2013, p. 71).

Os personagens dos romances não conheciam de fato o Pinhal da Azambuja e a Terra do Nunca, eles tinham uma imagem idealizada desses lugares, pois ouviram histórias e suas mentes criavam uma imagem ideal. Quando se deparou com o Pinhal da Azambuja, houve frustração da parte do narrador de Viagens, em contrapartida, quando se depararam com a Terra do Nunca, as crianças Darling provaram que a ilha era muito melhor do que haviam imaginado.

Por mais que a obra de Garrett deixe claro para o leitor que a narrativa é uma ficção e que a obra de Barrie afirme, quase que constantemente, que se trata de uma verdade camuflada ${ }^{3}$ por um "faz de conta", pode-se inferir que essa é uma maneira dos autores advertirem os leitores e exporem o ideal de que o romance não tem um compromisso com a verdade, que ele não tem por objetivo pintar a realidade.

De maneira geral pode-se dizer que as obras em estudo são teóricas, ou melhor dizendo, auto teóricas, e que apresentam temas semelhantes apesar de serem destinadas a públicos diferentes e apresentarem abordagens e estruturas distintas.

Visando a importância da autoteorização literária, a seguir será destacado o que os documentos oficiais falam sobre o ensino de literatura no Ensino Médio e será evidenciado de que maneira teoria e literatura podem dividir espaços iguais dentro de sala de aula.

\section{A autoteorização literária e suas relações com o ensino}

Compreende-se, de forma geral, que o papel do leitor no momento da experiência literária é de suma importância, pois, como aponta Jouve (2002, p. 61) em $A$ leitura, "a leitura, de fato, longe de ser uma recepção passiva, apresenta-se como uma interação produtiva entre o texto e o leitor". Partindo desse pressuposto, entende-se que, além da preocupação dos romancistas para com o leitor, os educadores devem ter em vista essa mesma preocupação, pois o texto necessita da contribuição do leitor, uma vez que se trata de uma estrutura incompleta, com espaços a serem preenchidos pelo leitor.

\footnotetext{
${ }^{3}$ Como pode-se perceber no seguinte trecho: "Nas histórias fantasiosas as pessoas conseguem conversar facilmente com os pássaros, e eu gostaria de poder fingir que essa história é assim e que Peter deu uma resposta para o Pássaro do Nunca. Mas a verdade é melhor, e eu só quero contar o que realmente aconteceu. Bom, não só eles não conseguiram se entender, como também deixaram as boas maneiras de lado". (BARRIE, 2013, p. 142).
} 
A discussão das obras literárias aqui proposta exige que seu leitor tenha um nível de leitura mais elevado em relação ao de um aluno de Ensino Fundamental 1, por exemplo. É por essa razão que se optou por trazer como fundamentação teórica para este artigo as Orientações Curriculares para o Ensino Médio. Sobre isso as OCEM (2007) dizem que:

\begin{abstract}
A Literatura como conteúdo curricular ganha contornos distintos conforme o nível de escolaridade dos leitores em formação. As diferenças decorrem de vários fatores ligados não somente à produção literária e à circulação de livros que orientam os modos de apropriação dos leitores, mas também à identidade do segmento da escolaridade construída historicamente e seus objetivos de formação. (OCEM, 2007, p. 61).
\end{abstract}

Por experiência própria sabe-se que a disciplina de literatura pode ser um tanto problemática. Essa é um fato que se repete muito e que é discutido dentro dos cursos de Letras e que nos leva a crer que esse fato não ocorra por total responsabilidade do aluno, mas, parcialmente - senão em grande parte -, daquele que o apresenta, do professor. Entende-se que há um problema de leitura em que se parte da história da literatura para a prática (leitura da obra ou fragmentos de tal). Para que os alunos leiam literatura a partir de uma postura crítica, é necessário que lhes sejam oferecidas as possibilidades.

Nesse sentido, entende-se que seria ideal que numa aula de literatura o professor apresentasse aos alunos a obra de fato e conduzisse a turma a discussões a partir do próprio texto literário, apresentando-lhes algo de crítica e teoria e não a partir das escolas literárias.

O estudo quase que exclusivo da história da literatura nas aulas de literatura gera um conflito, pois, segundo as OCEM (2007, p. 63):

Constata-se, de maneira geral, na passagem do ensino fundamental para o ensino médio, um declínio da experiência de leitura de textos ficcionais, seja de livros da Literatura infanto-juvenil, seja de alguns poucos autores representativos da Literatura brasileira selecionados, que aos poucos cede lugar à história da Literatura e seus estilos.

Toda a formação do leitor advinda do ensino fundamental decai ao seu ingresso no ensino médio, pois a obra literária passa a ocupar um papel secundário e a história da literatura passa a ser o alvo principal das aulas de literatura. Estudar as escolas literárias e a história da literatura é sim muito importante, porém, a forma com que se trabalha com esses temas deveria ser distinta para que não ocorra o que os próprios documentos advertem: "fragmentação de trechos de obras ou poemas isolados, considerados exemplares de determinados estilos, prática que se revela um dos mais graves problemas ainda hoje recorrentes". (OCEM, 2007, p. 63).

É comum que os professores apresentem aos alunos uma linha do tempo demarcando o período de cada escola literária e elencando suas características. O problema dessa abordagem é que o texto literário acaba sendo usado para reafirmar as características das escolas literárias. O aluno acaba buscando moldar as obras às escolas literárias, o que é um equívoco, uma vez que o movimento é reverso, as divisões das escolas vieram depois das obras. $\mathrm{O}$ aluno deve ser capaz de perceber isso, como também deve ser capaz de identificar que a teoria existe porque a literatura existe. 
Para que se trabalhe com a obra literária e com a teoria simultaneamente, propõem-se um trabalho com as obras autoteorizantes, pois a partir dessas obras professor e aluno terão em vista que a teoria nasce da literatura (e não vice-versa) e que a teoria não deve ser vista como um guia, como uma regra para o estudo literário. A partir das obras autoteorizantes os professores poderão abordar temas diversos, além de promover aos alunos um contato direto com a obra, dando, então, um papel de protagonista nas aulas de literatura.

Como visto anteriormente, a autoteorização está diretamente ligada a preocupação e educação do leitor. Acredita-se que essa deve ser uma preocupação também dos professores nas aulas de literatura, uma vez que uma obra é aberta a diversas significações, ressignificações, reflexões, etc. "[...] $\mathrm{Na}$ esperança de que os leitores achem a teoria valiosa e cativante e aproveitem para experimentar os prazeres da reflexão" (CULLER, 1999, p. 25), é importante que ela seja abordada a partir das próprias obras literárias, uma vez que a estrutura interna da obra proporciona uma leitura múltipla e não linear em que o leitor não busca um único significado.

\section{Considerações finais}

Depois de todas as reflexões aqui ponderadas, concluímos que trabalhar com obras autoteorizantes em sala de aula promove aos alunos um contato simultâneo entre literatura e teoria literária. Se a teoria for vista, por educador e educando, como procedente da literatura, ela poderá dividir espaços iguais com a obra literária nas aulas de literatura, deixando, assim, o protagonismo para a obra.

Pautando-se na ideia de que o texto depende do leitor, como aponta Jouve (2002), é importante que os alunos tenham acesso à obra literária propriamente dita, que percebam que a teoria nasce do texto literário e que uma obra possui inúmeros significados e sentidos.

Acreditamos que, se o aluno for capaz de identificar as diferentes "camadas" que uma obra oferece sem tentar encaixá-la em alguma escola literária, ele será capaz, também, de conceber a obra como o elemento principal da disciplina de Literatura. Acreditamos, ainda, que o leitor está em constante formação. Identificar o texto como ponto de partida já é um "lançar-se" no caminho da formação do leitor.

As obras aqui estudadas, Viagens na minha terra, de Almeida Garret, e Peter Pan, de James Matthew Barrie, são exemplos das tantas obras autoteorizantes existentes. Por fim, é importante dizer que o mecanismo da autoteorização é interessante e importante, pois a partir dele é possível discutir sobre literatura, narrador, tipos de leitor e diversos outros temas. Enfim, é teorizar.

\section{Referências bibliográficas}

BARRIE, J. M. Peter Pan. Tradução de Julia Romeu. 1ª ed. Rio de Janeiro: Zahar, 2013.

BRASIL. Linguagens, códigos e suas tecnologias. Orientações curriculares para o Ensino Médio, vol. 1. Brasília: Ministério da Educação, Secretaria de Educação Básica, 2006. 
CULLER, J. O que é teoria. In: Teoria literária: uma introdução. Tradução de Sandra Vasconcelos. São Paulo: Beca, 1999. P. 11-25.

ECO, U. Seis passeios pelos bosques da ficção. Tradução por Hildegard Feist. São Paulo: Companhia das Letras, 1994.

GARRETT, A. Viagens na minha terra. Edição dirigida e apresentada por Antônio Soares Amora. Rio de Janeiro: Ediouro; São Paulo: Publifolha, 1997.

JOUVE, V. A leitura. Tradução de Brigitte Hervot. São Paulo: Editora UNESP, 2002.

MOISÉS, M. Dicionário de termos literários. 12. ed. - São Paulo: Editora Cultrix, 2004.

ROUANET, S. P. (2007). A forma shandiana. Hipertrofia e subjetividade. In: Riso e Melancolia: a forma shandiana em Sterne, Diderot, Xavier de Maistre, Almeida Garrett e Machado de Assis. São Paulo: Companhia das Letras, 2007, p. 17-33; p. 46-59.

VOLOBUEF, K. Ironia romântica. In: Frestas e arestas. A prosa de ficção do romantismo na Alemanha e no Brasil. São Paulo: Fundação Editora da UNESP, 1999, p. $90-99$.

\section{Bibliografia Consultada}

BAUMAN, Z. A última palavra - e ela pertence à liberdade. In: $O$ mal-estar da pósmodernidade. Tradução de Mauro Gama, Cláudia Martinelli; revisão técnica de Luís Carlos Fridman. Rio de Janeiro: Jorge Zahar, 1998, p.246-257.

Sobre a verdade, a ficção e a incerteza. In: $O$ mal-estar da pósmodernidade. Tradução de Mauro Gama, Cláudia Martinelli; revisão técnica de Luís Carlos Fridman. Rio de Janeiro: Jorge Zahar, 1998, p.142-159.

JOUVE, Vincent. Por que estudar literatura? Tradução de Marcos Bagno e Marcos Marcionilo. São Paulo: Parábola, 2012.

LIMA, L. C. A questão do controle. In: $O$ controle do imaginário \& a afirmação do romance: Dom Quixote, As relações perigosas, Moll Flanders, Tristam Shandy. São Paulo: Cia das Letras, 2009, p.178-210.

Recebido em 21 de maio de 2019

Aceito em 25 de novembro de 2019 